\title{
Developing a Persian test battery of prereading skills for screening Preschool-aged children
}

\author{
Elaheh Akbari ${ }^{1}$, Abbas Ebadi $^{2}$, Mohammad Kamali $^{3}$, Yoones Amiri Shavaki*1, \\ Mehdi Dastjerdi Kazemi ${ }^{4}$
}

\section{Abstract}

Background: The lack of screening test battery has made it difficult for early identification and intervention of Persian-speaking children with risk of reading problems prior to formal education. The purpose of this study was to develop and introduce a Persian prereading test battery based on the multidimensional reading perspective for screening preschool children.

Methods: First, the predicators of reading skill and dyslexia along with the subscales of each predictor were identified through literature review and holding expert's panel. The batteries of tests were performed on 48 typically-developing children (5.6-6.6 years old) selected using the random (cluster) method. The Pearson correlation coefficient, item analysis and then reliability were measured.

Results: The 5-component test battery with 8 subtests was formed. Findings indicated there were moderate and significant correlations between subtests (all $r>0.4, p<0.001$ ). Internal consistency reliability for the subscales was 0.51 to 0.89 .

Conclusion: The Persian test battery of prereading skills including phonological awareness, identification of first and closing phonemes, visual discrimination skill, rapid automatic naming and phonological working memory may identify children who are at risk. A longitudinal study is warranted to evaluate its detailed psychometric properties.

Keywords: Reading, Literacy, Phonological awareness, Preschoolers, Screening

Conflicts of Interest: None declared

Funding: Iran University of Medical Sciences

\section{*This work has been published under CC BY-NC-SA 1.0 license. \\ Copyright $\odot \underline{\text { Iran University of Medical Sciences }}$}

Cite this article as: Akbari E, Ebadi A, Kamali M, Amiri Shavaki Y, Dastjerdi Kazemi M. Developing a Persian test battery of prereading skills for screening Preschool-aged children. Med J Islam Repub Iran. 2019 (10 Aug);33:81. https://doi.org/10.47176/mjiri.33.81

\section{Introduction}

Reading is a multi-faceted process, interacting with various language and cognitive skills (1). Children usually receive formal reading training at school, whereas prerequisites for reading such as phonological processing, perceptual processing and oral language skills are formed throughout early childhood (2). Therefore, deficits in anyone of these reading-related skills lead to reading difficulties or even dyslexia (3). If children with reading difficulties are not identified at early stages, educational attainment will be highly challenging resulting in the child

Corresponding author: Dr Yoones Amiri Shavaki, amirishavaki.y@iums.ac.ir

1. Department of Speech \& Language Pathology, School of Rehabilitation Sciences, Iran University of Medical Sciences, Tehran, Iran

2. Behavioral Sciences Research Center, Nursing Faculty, Baqiyatallah University of Medical Sciences, Tehran, Iran

3. Department of Rehabilitation Basic Sciences, School of Rehabilitation Sciences, Iran University of Medical Science, Tehran, Iran

4. Faculty of Psychology and Educational Sciences, Allameh Tabataba'i University, Tehran, Iran dropping out of school. It also may lead to considerable social, economic , cultural and mental-emotional damages (4). Therefore, various studies have emphasized the importance of early identification of children at risk for reading/literacy difficulties; many of them have tried to develop and validate tests able to predict children with probable reading difficulties (5).

Outside Iran, there are various tools for screening emergent literacy skills at preschool ages, including the Test of Preschool Early Literacy (TOPEL) (6), the Dynamic Indi-

$\uparrow$ What is "already known" in this topic:

Various studies have tried to develop and validate tests able to predict children at risk for reading difficulties. It is revealed that the quantitative research alone without any qualitative results, and vice versa, may lead to the selection of variables only on the basis of a hypothesis.

$\rightarrow$ What this article adds:

This study developed the test battery of prereading skills for screening Persian language children at preschool ages. The development of this test battery is based on a multidimensional perspective. 
cators of Basic Early Literacy Skills (DIBELS) (5), and the Revised Get Ready to Read (GRTR-R) (7) and Get it, Got it, Go! (GGG) (8). These tools can predict the success of children's reading in the next years. TOPEL is used for ages 3 to 5 years with 3 subtests of print knowledge, definitional vocabulary, and phonological awareness (6). While the GRTR evaluates phonological awareness and print knowledge (7) the DIBELS evaluates two skills of alphabetic knowledge and phonological awareness(5). The GGG evaluates two skills of phonological awareness and descriptive vocabulary treasury (8). These tools are easily applicable in a short time. However, they evaluate a small number of components and ignore all major areas related to reading such as oral language and the rapid naming (9).

In Iran, limited studies have been conducted to develop a screening tool for the early detection of children at risk of reading problems at preschool ages. Shahrami et al. (2001) developed a tool for screening the educational readiness of 6-year-old children using three Farsi tests, which include three cognitive, motor and social domains (10). One of the limitations of this test is that it does not evaluate phonological awareness and oral language as the most important skills associated with reading and literacy. In addition, the names of the final subtests and their number have not been reported in their study.

MeheriNejad et al. (2012) studied the application of the Bender Gestalt Test to predict the reading disorder and dictation of preschool children (11). This test evaluates visual-motor perception in the children. Although the results of their study showed the rate of errors in children with reading disorder shown to be higher, the results of study was not very reliable because the children with reading disorder were identified based on the judgment of the teacher on reading skill, and the inconsistent grading system in the class.

The process of selecting subtests is an important issue that has been underestimated in the development of some foreign and domestic screening tools. In addition, the results of quantitative research alone without any qualitative results, and vice versa, may lead to the selection of variables only on the basis of a hypothesis, resulting in the lack of adequate, comprehensive intervention (12). Therefore, it seems that a combination of quantitative and qualitative methods is useful for choosing reading-related components for screening, since using the approach of mixed method can provide a more complete picture of the subject (12) .

Another important issue in preschool children is the challenging evaluation of awareness and understanding about literacy concepts especially those with disabilities, so it is suggested in the literature that evaluation of abstract issues such as literacy be performed by assessment batteries which cover different aspects instead of using a specific test for a special skill (13).

Considering the aforementioned issues there is great concern about assessment tools which can evaluate all children using the same standards regardless of their present capabilities (14). To the best of our knowledge, there is no early screening reading tool in Persian language. Therefore, a comprehensive test battery including cogni- tive-language abilities and nonverbal visual and motor skills for early detection of deficits in reading and literacy in preschool-aged children seems necessary to avoid the mentioned concerns. The present study aimed to develop and introduce a test battery of reading-related skills for preschool aged children $(5.6-6.6$ years old). This battery is intended for early identification of children at risk for reading difficulties.

\section{Methods}

\section{Design and Participants}

This was a methodological research. Forty eight children participated at Step 4 of the study in which item analysis was carried out. A total number of 48 Persianspeaking children aged 5.6-6.6 years were recruited for the pilot study but six boys withdrew due to summer holiday and absenteeism (Schooling is compulsory in Iran for children who become seven years of age at the beginning of the fall on 22 September). Thus, a total number of 42 preschool children ( 27 girls and 15 boys, mean age $=73.3$ months, SD = 4.37), participated in April 2016. Sampling was carried out using the cluster method. The city of Tehran was first divided into three geographical areas of north (region 2), center (region 7), and south (region 15), from which one preschool was selected randomly for representing the socio-economical and socio-cultural status of the participants. Inclusion criteria were monolingual Persian, IQ $>90$ based on Raven Intelligence Test (15) with no physical and psychological problems. Children with seizures and developmental disorders were excluded from this study. It should be noted that the information about the health of each child was provided through interviews with caregivers and parents, available profiles in preschoolers, along with the observations and evaluations performed by a speech and language pathologist. Parents or caregivers of the children signed informed consent form prior to study process. The study protocol was approved by the Ethics Committee of Iranian University of Medical Sciences.

This study consisted of two parts. The first part included the development of a screening test battery and the second part involved the study of a larger sample with the calculation of the construct and criterion validity. The second part will be presented later in another paper. Since the method of developing the test battery was slightly different from developing common tools, the steps for Persian prereading test battery development were conducted based on the process of test development, to which have been referred in the literature $(16,17)$.

The process is composed of 6 steps. The 4 steps followed in this study are presented here in order.

Step 1: Overall plan

The lack of prereading screening test battery with appropriate validation features has made it difficult to identify, prevent, and interfere with ordinary Persian language children at risk of reading difficulties before formal education. Therefore, developing and validating the test battery of prereading skills screening for Persian language children at preschool ages is essential. The development of this test battery was based on a multidimensional per- 
spective $(5,18)$. According to this attitude, in addition to the phonological awareness as a prerequisite for learning; other components also may play an important role in predicting reading $(5,18)$. Hence the general format of the test battery was defined as the prereading screening test of paper and pencil, which some of its subtests use visual stimulus (pictures) and other subtests uses listening stimulus (questioning) to stimulate the child to answer in the form of pointing or a verbal response.

Step 2: content definition

In this step, the integrated review of the literature and the expert panel holding were done to identify what skills and sub-skills can predict reading and reading difficulties.

Step2.1. Literature review

At this phase, the papers and books ranging from 1970 to 2017 with a combination of keywords related to prerequisite skills of reading, dyslexia, early literacy, anticipation, screening, and preschool were searched in the databases as well as accessible foreign and domestic electronic papers through the academic and non-academic digital networks. Foreign databases, including PubMed, PROQUEST, OVID, SCOPUS, WEB OF SCIENCE, Psycho INFO, and domestic databases, including Medlib, SID, Magiran, Iran Docs, and Iran Medex were searched. Of the relevant domains, the components with a minimum correlation of 0.3 , reading skill and dyslexia were extracted from the literature (19). In addition, the screening tools of early reading and literacy were also explored and their subscales extracted.

Research team conclusion was based on existing literature, eight components including alphabetic knowledge, phonological awareness (PA) and orthographic skill (2022), RAN (23-25), phonological working memory (PWM) $(20,26)$, oral language skills $(27)$, and visual processing (28) as the strong predictors of reading and reading difficulties; while motor skills had moderate correlation with reading ability (22).

Research team excluded 5 subtests including letter identification and naming (alphabetic knowledge), sound segmentation, rapid naming of digits and letters skills from battery's tests because children were supposed to receive no training on such literacy skills prior to school age (7 years old). Also, orthographic skills (print knowledge) and visual attention were excluded due to lack of proper tests, in addition to rhyme, syllable identification, syntax and narrative skills were excluded because of appropriateness of these skills for children less than 5-year old $(22,29)$.

Step 2.2. Expert panel

The opinion of 16 experts was sought online and in person about the importance of 6 components and 20 subskills for being involved in the screening test battery. Of these sixteen experienced experts in the field of literacy and dyslexia in Iran, 12 people including eight speech and language pathologists, two occupational therapists and two psychologists participated in the survey. Experts were selected based on their publications and research and/or clinical expertise. The participants were asked to score each 6 components (the least importance $=1$ and the most importance $=6$ ) and each 20 extracted sub-skill (the least importance $=1$ and the most importance $=20$ ). Experts were given the opportunity to write their comments or suggestions at the end. The experts were also asked to add other predictive skills which may not exist in the presented list if there was any.

Step 3: Test specification

In this step, the test battery characteristics were determined. To develop a screening test battery, it was necessary to use other valid tools. Thus, six criteria were used to select a test or its subtests. The criteria included (1) the type of paper and pencil used; (2) assessment of children at the age range of 5 to 6 years and 6 months; (3) ease of implementation; (4) performance in a short time; (5) an easy scoring; and (6) having good psychometric properties.

Step 4: Item development

This step included two phases of subtest for determination and reduction.

Step. 4.1. Subtest determination

Given that the purpose of this study was to develop a screening test battery through the other valid tools, so at this phase, instead of producing items, subtests were determined. For this purpose, all of the existing tests were first collected to measure sub-skills extracted from the literature review and expert panel. Finally, the following 20 scales which had 5 above- mentioned criteria were selected from different tests.

1-Phoneme blending, 2-First phoneme identification and 3-Closing phoneme identification subtests from the Phonological Awareness Test (30), 4-Forward digit span and 5- Backward digit span from the Persian version of The Wechsler Intelligent Scale for Children (WISC-III) (31), 6-Color naming and 7- Object naming subtests from the Rapid Automatic Naming Test (32), 8-Picture vocabulary subtest from the Persian version of Test of Language Development-III (Persian-TOLD-3) (33), 9- Word definition and 10- Similarities subtests from the Persian version of The Wechsler Intelligent Scale for Children (WISC-III) (31), 11- visual discrimination, 12-visual memory, 13visual spatial-relationships, 14-visual form-constancy, 15visual sequential-memory, 16- visual figure-ground discrimination, and 17- visual closure subtests from Persian version of Test of Visual Perception Skills Revised (TVPS-R) (34), 18-standing on one foot with open eyes and 19-Touching thumb to finger tips subtests from the Linklon Oseresky Motor Development Scale (LOMOS) (35) and 20-hopping task from the Test of Gross Motor Development (TGMD) (36) were selected.

Step.4.2. Subtest reduction

In this phase to reduce the subtests, two sub-phases were performed.

Step. 4.2.1. Correlation testing

The first version of the test battery with20 subtests was administered to 42 children.

Initially, the difference of prereading skills between male and female groups was investigated by independent t-test and the sample was not separated in terms of gender because no difference found between the two groups in all sub-tests. The Correlation among prereading skills including PA, PWM, RAN, vocabulary, visual perception, and motor skills was assessed by Pearson correlation test. Co- 
efficient values between 0.8 and 1 were considered very high, between 0.6 and 0.8 high, between 0.4 and .6 acceptable, and values below 0.4 indicated low correlation (19). Since PA, the strongest predictor of reading skill in alphabetic languages (37-40), and non-alphabetic languages (40-42), its correlation with other subtests were considered in the present study. Hence, the subtests with correlation coefficients and phonological awareness under 0.4 were deleted. Of 20 subtests, 8 cases were eliminated.

Step 4.2.2. Item analysis and reliability

The remaining twenty subtests from the previous phase were analyzed based on difficulty index, discrimination index, the Item-Total correlations and Cronbach's alpha coefficients or Kuder Richardson 21 to assess internal consistency. The acceptable range for the degree of difficulty was 0.3 to 0.7 , the degree of discrimination 0.5 or higher and for correlation coefficient 0.3 or higher (19), and the items with three or two parameters were remained in the study. According to previous studies, Cronbach's alpha coefficients values between 0.70 and 0.80 were considered high, 0.60 and 0.69 acceptable, and lower than 0.50 considered poor reliability (43).

\section{Measures}

Phonological Awareness: Three subtests of the Phonological Awareness Test (30), were selected for the present study including phoneme blending, phoneme identification of first and closing phoneme. To evaluate phoneme blending, the identification of the initial phoneme and the identification of the end phoneme were used from three sub-tests of the phonological awareness test. Each measure had 10 items with at highest score of 10 . Phoneme blending subtest: the phonemes forming the target word were uttered by about two second intervals and children were made to point the target image from 10 given images upon hearing the sound. On battery identification: children were also requested to name the three showed pictures. Then, children pointed to the two pictures with similar on batteries. Identification of closing phoneme: similar to the battery identification task, and three pictures were shown to the children for naming. Afterward children pointed to the two pictures with similar closing phonemes.

Phonological working memory (PWM): To measure PWM, two subtests of ordered and reversed figures span were utilized from the Persian version of The Wechsler Intelligent Scale for Children (WISC-III) (31). In both subtests, children were required to listen to a series of digits with one second interval. Then they were asked to repeat the digits in order or in reverse depending on the nature of the subtest.

Rapid Automatic Naming (RAN): The color and object naming subtests of the RAN test (32) were utilized to assess rapid naming speed. In each subtest, five familiar items (color or objects) were randomly repeated 10 times on a card making a total of 50 items on each card. The child was required to name all items as fast as they could. A stop watch was used to record the overall time on each card per second. Errors were also recorded and score of each subtest calculated based on the time spent for naming all the items per second.
Vocabulary: Three measures including picture vocabulary subtest from the Persian version of Test of Language Development-III (Persian-TOLD-III) (33), Word definition and similarities subtests were utilized from the Persian version of The Wechsler Intelligent Scale for Children (WISC-III) (31) to evaluate used vocabulary. Picture vocabulary: In the subtest picture vocabulary with 30 items, was shown to children and required them to point the target image among three given images after they heard the word. Word definition: In word definition, children were asked to give definition of the heard word and after five incorrect responses, test was terminated. Similarities: In similarities, children were asked to say similarities between two given words and after three incorrect responses, test was terminated.

Visual perception: Persian version of Test of Visual Perception Skills Revised (TVPS-R) (34)was utilized to evaluate visual perception. This test included seven subtests of visual discrimination, visual memory, visual spatial-relationships, visual form-constancy, visual sequential-memory, visual figure-ground discrimination, and visual closure suitable for 4-13 years old children in which each subtest contained 16 items. In each item, an image was first shown to the child followed by repeating that image in a series of five images. Children were required to select one from five images (maximum 16 scores). After every four consecutive errors, test was stopped.

Motor skills: Motor skills was assessed with three tasks: Standing on one foot with open eyes and Hopping task from the Persian version of TGMD (36) for evaluating balance and touching thumb to finger tips task from LOMOS (35) and fine motors. In the task of standing on one foot with open eyes, children were asked to stand on one foot for five seconds while leaving the hands next to the legs. This movement was repeated up to two times for each foot separately. Correct movement at first time acquired 3 and, if they performed the movement correctly at second time 2 scores.

In touching thumb to fingertips task, children were asked to touch their finger by the thumb task started from the little finger, and continued in reverse. Also, it started once more from the thumb to the little finger. Time for completing each task was determined 5 seconds. This task was repeated up to two times for each hand separately. Three marks belonged to correct performance of the task at first time and 2 marks were specified for correctly performing the task at second time.

For testing balance, the hopping task from TGMD (36) was used and flawless performing the task awarded one score to children for each foot. The children were asked to jump a path on one leg and a score was given for each right move without losing balance for each leg.

\section{Test battery administration and scoring}

Principal researcher administered tests individually for each child in preschool institute. The first version of the test battery involving all tools was administered in three separate, 20-30 minutes sessions over one week in order to prevent fatigue. Tests were performed in a same order across all participants during test sessions. 
The final version of prereading screening test battery included 7 sub-tests, and considering two RAN sub-tests as two items, the total of the test had 50 items. The method of implementing each subtest and its scoring was similar to the tools used (how to implement and score are explained in the section of "Measures"). Except the subtests of the rapid naming of colors and objects, in which the time was recorded in seconds, the scoring system for the rest of subtests represented by grading and a score was given for each correct answer. The overall time to implement the test battery was 15 to 20 minutes.

\section{Data analysis}

Statistical tests used included Kolmogorov-Smirnov test (normality of the data), independent t-test (comparison of prereading skills in both male and female groups), Pearson's correlation test (correlation between subtests), Spearman correlation coefficient (item analysis), and Cronbach's alpha coefficients or Kuder-Richardson 21 (internal consistency). All statistical analysis was performed using SPSS 17 with the significance level as < 0.05 .

\section{Results}

Kolmogorov-Smirnov test showed normal distribution of all subtests $(p>0.05)$. The data were normal with the skewness being in the range of 1 to 0.6 .

Test content: Considering the fact that the content validity of the tests has been calculated in previous studies, content validity was performed qualitatively in this study. Expert panel view of the importance of the presence of skills and sub-skills and their relevance with reading and reading difficulties indicated highest mean score for PA (19.19 score of 20 score, 97\%) and lowest score was given to motor skills (12.28 score of 20,54\%). Since mean score of importance for prereading skills was higher than 50 percent, all of 20 sub-skills including phoneme blending, first phoneme identification, closing phoneme identification, forward \& backward digit span, similarities, picture vocabulary, oral vocabulary, visual discrimination, visual memory, visual spatial-relationships, visual formconstancy, visual sequential-memory, visual figureground discrimination and visual closure, RAN of objects $\&$ colors, similarities and oral vocabulary, touching thumb to fingertips, standing on one leg \& hopping were selected. Results of the Pearson correlation test on the pilot study data is presented in Table 1 .

Data analysis showed moderate to high significant correlation of PA measure with all other measures (all $r>0.4$, $\mathrm{n}=42, \mathrm{p}<0.01$ ) except motor skill measures. PA had the highest correlation with visual perception $(\mathrm{r}=.92)$ but, PWM had the least correlation $(\mathrm{r}=0.44)$. The phoneme blending, first and closing phoneme identification subtests were significantly correlated with each other and with backward digit span, visual figure-ground, visual discrimination, visual sequence memory, visual form-constancy, rapid naming of colors and objects, similarities and oral vocabulary $(r>0.4, p<0.05) \quad$ (Table 2$)$. As a result, items of these subtests were analyzed at the next step.

Item analysis: Results showed that 7 subtests including phoneme blending, first and closing phoneme identification, visual discrimination, rapid color naming, similarities and forward digit span were confirmed. Other measures were removed from the assessment battery due to their poor psychometric properties (Table 3).

Test battery reliability: Coefficient of Cronbach's alpha for its subtests before item analyses was 0.45 to 0.89 and 0.51 to 0.89 after it.

Table 1. Correlations between all core domains used in the study $(\mathrm{N}=42)$

\begin{tabular}{|c|c|c|c|c|c|c|c|c|}
\hline & Mean & $\mathrm{SD}$ & 1 & 2 & 3 & 4 & 5 & 6 \\
\hline 1. Phonological awareness & 14.83 & 6.99 & - & $0.44^{* *}$ & $0.92^{* *}$ & $-0.49^{* *}$ & $0.69^{* *}$ & -0.09 \\
\hline 2. Phonological memory & 4.73 & 2.00 & & - & 0.43 & $-0.44^{* *}$ & $0.33^{*}$ & -0.01 \\
\hline 3. Visual perception & 50.41 & 15.76 & & & - & -0.45 & $0.73^{* *}$ & 0.24 \\
\hline 4. Rapid automatic naming & 167.69 & 43.38 & & & & - & $-0.45^{* *}$ & 0.05 \\
\hline 5. Vocabulary & 39.14 & 7.81 & & & & & - & -0.26 \\
\hline 6. Motor skills & 10.52 & 10.71 & & & & & & - \\
\hline
\end{tabular}

$* \mathrm{P}<0.05, * * \mathrm{P}<0.01$

\begin{tabular}{|c|c|c|c|c|c|c|c|c|c|c|c|c|c|c|c|c|c|c|c|c|}
\hline & PB & FPI & CPI & FDS & BDS & VD & WM & $\begin{array}{l}\text { VSR } \\
\end{array}$ & $\begin{array}{l}\mathrm{VFC} \\
\end{array}$ & VSM & $\begin{array}{l}\text { VFG } \\
\end{array}$ & $\mathrm{VC}$ & RO & $\mathrm{RC}$ & $\mathrm{PV}$ & SI & OV & TTF & SOL & Hop \\
\hline PB & - & $0.51^{* * 1}$ & $0.49^{* * *}$ & $0.34^{*}$ & $0.45^{*+1}$ & $0.51^{* *}$ & 0.18 & 0.15 & $0.77^{* *}$ & $0.66^{*}$ & $0.75^{* * *}$ & 0.49 & -0.25 & $-0.39^{* *}$ & 0.28 & $0.50^{* *}$ & $0.37^{*}$ & -0.18 & -0.08 & 0.20 \\
\hline FPI & & - & $0.60^{* * *}$ & 0.22 & 0.21 & $0.31^{*}$ & 0.05 & 0.19 & 0.12 & 0.14 & 0.22 & -0.00 & -0.17 & $-0.31^{*}$ & 0.16 & $0.44^{* *}$ & $0.55^{* *}$ & 0.03 & 0.05 & 0.26 \\
\hline CPI & & & - & 0.22 & 0.28 & $0.40^{* *}$ & 0.09 & 0.00 & 0.31 & 0.40 & $0.57^{*}$ & 0.55 & $-0.50^{* *}$ & $-0.62^{* *}$ & 0.20 & $0.57^{* *}$ & $0.60^{* *}$ & -0.08 & -0.13 & 0.12 \\
\hline FDS & & & & - & $0.33^{*}$ & 0.13 & $0.35^{*}$ & -0.14 & 0.04 & -0.14 & -0.07 & 0.17 & -0.22 & $-0.40^{* *}$ & $0.37^{*}$ & 0.10 & 0.29 & -0.08 & 0.10 & 0.22 \\
\hline BDS & & & & & - & $0.45^{* *}$ & 0.22 & 0.07 & $0.78^{* *}$ & $0.63^{*}$ & 0.29 & 0.33 & -0.19 & $-0.44^{* *}$ & 0.21 & 0.20 & 0.13 & 0.01 & 0.04 & 0.16 \\
\hline VD & & & & & & - & 0.25 & 0.14 & $0.67^{*}$ & 0.49 & 0.25 & 0.27 & -0.20 & -0.23 & $0.43^{* *}$ & $0.37^{*}$ & 0.28 & -0.03 & -0.03 & 0.16 \\
\hline VM & & & & & & & - & $-0.36^{*}$ & 0.16 & -0.24 & -0.23 & 0.34 & -0.10 & -0.16 & $0.34^{*}$ & 0.10 & 0.16 & 0.07 & 0.14 & $0.40^{* *}$ \\
\hline VSR & & & & & & & & - & $0.57^{*}$ & 0.39 & 0.29 & -0.08 & 0.21 & 0.10 & 0.08 & 0.06 & -0.13 & -0.02 & -0.01 & -0.28 \\
\hline VFC & & & & & & & & & - & $0.68^{*}$ & 0.43 & 0.39 & -0.03 & -0.25 & $0.61^{*}$ & 0.49 & 0.02 & 0.10 & 0.08 & -0.18 \\
\hline VSM & & & & & & & & & & - & $0.69^{*}$ & 0.23 & -0.12 & -0.27 & 0.49 & 0.45 & 0.38 & 0.08 & -0.16 & -0.09 \\
\hline VFG & & & & & & & & & & & - & 0.31 & -0.37 & -0.55 & 0.50 & $0.71^{* *}$ & 0.22 & -0.06 & 0.04 & 0.22 \\
\hline VC & & & & & & & & & & & & - & $-0.57^{*}$ & $-0.67^{*}$ & 0.17 & 0.23 & 0.08 & 0.42 & 0.35 & 0.21 \\
\hline RO & & & & & & & & & & & & & - & $0.68^{* *}$ & -0.22 & -0.21 & -0.19 & -0.01 & -0.10 & $-0.42^{* *}$ \\
\hline $\mathrm{RC}$ & & & & & & & & & & & & & & - & -0.22 & $-0.45^{* *}$ & $-0.31^{*}$ & 0.18 & -0.13 & $-0.42^{* *}$ \\
\hline PV & & & & & & & & & & & & & & & - & 0.14 & 0.17 & 0.00 & 0.26 & 0.17 \\
\hline SI & & & & & & & & & & & & & & & & - & $0.51^{* *}$ & $-0.32^{*}$ & -0.26 & 0.23 \\
\hline OV & & & & & & & & & & & & & & & & & - & -0.26 & -0.16 & 0.20 \\
\hline TTF & & & & & & & & & & & & & & & & & & - & 0.21 & 0.14 \\
\hline SOL & & & & & & & & & & & & & & & & & & & 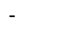 & 0.30 \\
\hline Hop & & & & & & & & & & & & & & & & & & & & - \\
\hline
\end{tabular}

Note: PB, Phoneme Blending; FPI, First Phoneme Identification; CPI, Closing Phoneme Identification; FDS, Forward Digit Span; BDS, Backward Digit Span; VD, Visual Discrimination; VM, Visual Memory; VSR, Visual Spatial-Relationships; VFC, Visual Form-Constancy; VSM, Visual Sequential-Memory; VFG, Visual Figure-Ground; VC, Visual Closure; RO, RAN Objects; RC, RAN Colors; PV, Picture Vocabulary; SI, Similarities; OV, Oral Vocabulary; TTF, Touching Thumb to Fingertips; SOL, Standing on One Leg; Hop, Hopping. $* \mathrm{P}<0.05, * * \mathrm{P}<0.01$. 


\begin{tabular}{|c|c|c|c|c|c|c|c|}
\hline Subtests & $\begin{array}{l}\text { Number of } \\
\text { items }\end{array}$ & $\begin{array}{l}\text { Difficulty } \\
\text { Index }\end{array}$ & $\begin{array}{l}\text { Discrimina- } \\
\text { tion Index }\end{array}$ & $\begin{array}{c}\text { Range of } \\
\text { item/ total } \\
\text { correlations }\end{array}$ & $\begin{array}{c}\text { Number of } \\
\text { deleted item }\end{array}$ & $\begin{array}{l}\text { Coronbach's } \\
\text { alpha }\end{array}$ & $\begin{array}{l}\text { Coronbach's alpha } \\
\text { after item deleted }\end{array}$ \\
\hline Phoneme Blending & 10 & $0.4-0.8$ & $0.3-0.7$ & $0.57-0.80$ & 0 & 0.89 & 0.89 \\
\hline First Phoneme Identity & 10 & $0.3-0.8$ & $0.2-0.7$ & $0.39-0.72$ & 3 & 0.76 & 0.76 \\
\hline Closing Phoneme Identity & 10 & $0.1-0.4$ & $0.1-0.5$ & $0.41-0.56$ & 2 & 0.60 & 0.62 \\
\hline Backward Digit Span & 7 & $0.2-0.8$ & $0.3-0.5$ & $0.80-0.82$ & 5 & 0.45 & 0.51 \\
\hline Visual Discrimination & 16 & $0.1-0.9$ & $.02-0.4$ & $0.36-0.59$ & 4 & 0.66 & 0.68 \\
\hline Visual Form-Constancy & 16 & $0.08-0.9$ & $-0.1-0.6$ & $0.59-0.77$ & 10 & 0.76 & 0.77 \\
\hline Visual Sequential-Memory & 16 & $0-0.8$ & $0-0.8$ & $0.66-0.86$ & 10 & 0.53 & 0.52 \\
\hline Visual Figure-Ground & 16 & $0.08-0.9$ & $0-0.6$ & $0.32-0.82$ & 10 & 0.72 & 0.77 \\
\hline Similarities & 17 & $0.07-0.8$ & $0.1-0.4$ & $0.36-0.72$ & 8 & 0.75 & 0.75 \\
\hline Oral Vocabulary & 32 & $0-1$ & $0-0.6$ & $0.34-0.73$ & 26 & 0.67 & 0.68 \\
\hline
\end{tabular}

\section{Discussion}

The results introduce a test battery of prereading skills, with a multi-dimensional view, as the first Iranian tool (Persian language) for early screening of children at risk for reading difficulties. This assessment battery covers many components, including PA (phoneme blending and identifying of first and closing phoneme), RAN (colors and objects), PWM (backward digit span), visual perception (visual discrimination) and vocabulary (similarities). While the DIBELS, GRTR, GGG and TOPEL have fewer components and they do not involve other reading-related components like RAN, PWM, and visual perception. The results indicate that the Persian prereading screening test battery is a validated and reliable tool. In addition, the time required to implement the given test battery was 15 to 20 minutes; this duration is longer than GGG and GRTR time, because these tests have a small number of subtests. For example GRTR-R is implemented in 10 minutes and has 25 items (7), but the prereading screening test battery has 50 items.

Another important advantage of the screening test battery is the easy method of implementing its subtests; while the DEBELS phonological awareness subtest need to be taught (the children are taught to say silently meaningless words) (5). In contrast, DEBELS measures alphabetic knowledge as an important predictors of reading, but this test was not included in the current battery because Persian children do not receive alphabetic knowledge formally before school, although some children may have this skill learned from their surroundings.

In the present study, there were considerable moderate to high correlation between 7 subtests of final test battery. As a result, this tool provides a set of prereading skills to determine the future success of reading. In addition, another important feature of this test battery was the use of tools with good psychometric properties and the internal consistency of their subtests with the Cronbach alpha method presented as high to very high. In this study, except for the 3 subtests that were acceptable, other subtests had a high internal consistency. There was no significant change in internal consistency of subtests after item deletion probably due to removal of a lot of questions because of the dependency of alpha coefficient on number of items (19). Like GRTR and GGG, the internal consistency of the present test battery was high. Internal consistency reliability for the GRTR-R was 0.88 (7) and for GGG was 0.78 (8).
Moreover, the cutoff point of the present test battery was not determined, due to the samples of study which included preschool children with no reading ability, and therefore it is necessary to calculate later the cutoff point of the prereading test battery in a next study. Another limitation of the study was the lack of a test for measuring orthographic knowledge, because the results of the studies conducted abroad indicate that this skill played an important role in predicting reading and screening children at risk of reading problems. Given that orthographic knowledge is dependent on language and culture, it is suggested that some research should be conducted to develop such a tool for the Persian language children.

\section{Conclusion}

The Persian test battery of prereading skills battery as a comprehensive measurement tool can be used to help specialists in identifying preschool children that weak in prereading skills and at risk for reading difficulties. Furthermore, future longitudinal studies on detailed evaluation of different aspects of psychometric properties such as predictive validity on a larger sample size are warranted.

\section{Acknowledgements}

The authors extend thanks to the children, families and experts involved in this study. Gratitude is expressed towards the Vice Chancellor for Research \& Technology of Iran University of Medical Sciences for financial support in the implementation of this project.

\section{Conflict of Interests}

The authors declare that they have no competing interests.

\section{References}

1. Cecilia MR, Vittorini P, Cofini V, di Orio F. The Prevalence of Reading Difficulties among Children in Scholar Age. Styles Commun. 2014;6(1).

2. Purpura DJ, Hume LE, Sims DM, Lonigan CJ. Early literacy and early numeracy: The value of including early literacy skills in the prediction of numeracy development. J Exp Child Psychol. 2011;110(4):647-58.

3. Elwér Å, Keenan JM, Olson RK, Byrne B, Samuelsson S. Longitudinal stability and predictors of poor oral comprehenders and poor decoders. J Exp Child Psychol. 2013;115(3):497-516.

4. Snowling MJ. Early identification and interventions for dyslexia: a contemporary view. J. Res. Special Educ Needs. 2013;13(1):7-14.

5. Goldstein H, Olszewski A, Haring C, Greenwood CR, McCune L, Carta J, et al. Efficacy of a supplemental phonemic awareness curriculum to instruct preschoolers with delays in early literacy 
development. J Speech Lang Hear Res. 2017;60(1):89-103.

6. Hilbert DD, Eis SD. Early intervention for emergent literacy development in a collaborative community pre-kindergarten. Early Child Educ J. 2014;42(2):105-13.

7. Farrington $\mathrm{AL}$, Lonigan CJ. Examining the measurement precision and invariance of the revised get ready to read! J Learn Disabil. 2015;48(3):227-38

8. Ball CR, Trammell BA. Response $\square$ to $\square$ intervention in high $\square$ risk preschools: Critical issues for implementation. Psychol Sch. 2011;48(5):502-12.

9. Spencer EJ, Spencer TD, Goldstein H, Schneider N. Identifying early literacy learning needs. Early childhood literacy: The national early literacy panel and beyond. 2013:45-70.

10. Shahrami A, Motaqhiani R. developing of a screening test for 6year-old children's educational readiness. JOEC. 2002;4(2):161-70.

11. Mehrinejad S, Sobhi G, Rajabi MS. An investigation of the power of the bender geshtalt test in the prediction of preschool children's predisposition for dyslexia and dysgraphia. J Learn Disabil. 2012;1(3):118-30.

12. Creswell JW. Research design: Qualitative, quantitative, and mixed methods approaches: Sage publications; 2013.

13. Flanagan DP, Alfonso VC, Dixon SG. Cross-Battery Approach to the Assessment of Executive. Handbook of Executive Functioning. 2013:379.

14. Halliday-Wynes S, Misko J. Assessment issues in VET: minimising the level of risk: NCVER Adelaide; 2013.

15. Akbarollah Khan K. Measuring Child's Intelligence: Children's Raven Test. Psychometric Publishing. 2015.

16. Haladyna TM, Downing SM. Handbook of test development: Routledge; 2011.

17. Manual A. Manual for Language Test Development and Examining. For use with the CEFR Produced by ALTE [Association of Language Testers in Europe] on behalf of the Language Policy Division, Council of Europe. 2011.

18. Pennington BF, Santerre-Lemmon L, Rosenberg J, MacDonald B, Boada R, Friend A, et al. Individual prediction of dyslexia by single versus multiple deficit models. J Abnorm Psychol. 2012;121(1):212.

19. Kellar PS, Kelvin E. Munro's statistical methods for health care research: Wolters Kluwer Health/Lippincott Williams \& Wilkins; 2012

20. Carroll JM, Solity J, Shapiro LR. Predicting dyslexia using prereading skills: the role of sensorimotor and cognitive abilities. J Child Psychol Psychiatry. 2016;57(6):750-8.

21. Gellert AS, Elbro C. Does a dynamic test of phonological awareness predict early reading difficulties? A longitudinal study from Kindergarten through grade 1. J Learn Disabil. 2017;50(3):227-37.

22. Thompson PA, Hulme C, Nash HM, Gooch D, Hayiou $\square$ Thomas E, Snowling MJ. Developmental dyslexia: predicting individual risk. J Child Psychol Psychiatry. 2015;56(9):976-87.

23. Georgiou GK, Tziraki N, Manolitsis G, Fella A. Is rapid automatized naming related to reading and mathematics for the same reason (s)? A follow-up study from kindergarten to Grade 1. J Exp Child Psychol. 2013;115(3):481-96.

24. Liao CH, Deng C, Hamilton J, Lee CSC, Wei W, Georgiou GK. The role of rapid naming in reading development and dyslexia in Chinese. J Exp Child Psychol. 2015;130:106-22.

25. Pan J, McBride-Chang C, Shu H, Liu H, Zhang Y, Li H. What is in the naming? A 5-year longitudinal study of early rapid naming and phonological sensitivity in relation to subsequent reading skills in both native Chinese and English as a second language. J Educ Psychol. 2011;103(4):897.

26. Perez TM, Majerus S, Poncelet M. The contribution of short-term memory for serial order to early reading acquisition: Evidence from a longitudinal study. J Exp Child Psychol. 2012;111(4):708-23.

27. Cabell SQ, Justice LM, Konold TR, McGinty AS. Profiles of emergent literacy skills among preschool children who are at risk for academic difficulties. Early Child Res Q. 2011;26(1):1-14.

28. Germano GD, Reilhac C, Capellini SA, Valdois S. The phonological and visual basis of developmental dyslexia in Brazilian Portuguese reading children. Front Psychol. 2014;5.

29. Carroll JM, Mundy IR, Cunningham AJ. The roles of family history of dyslexia, language, speech production and phonological processing in predicting literacy progress. Dev Sci. 2014;17(5):727-42.

30. Dastjerdi M, Soleymani Z. Phonological awareness test. Tehran: JOEC. 2003;6(4):951-4.
31. Jazayeri a. Reliability and validity of wechsler intelligence scale for children-(WISC-III) in Iran. J Med Educ. 2009;2(2).

32. Soleymani Z, Barkhordar A, Moradi A, Jalaee S. Designing and measuring the validity and reliability of rapid automatized naming test in the first-grade students. J Mod Rehabil. 2007;1(2):1-6.

33. Hasanzadeh S, Minaiee A. Adaptation and standardization of language development test TOLD-P: 3 for persian language children. Tehran: JOEC. 2001.

34. Dehghan A. Standardization of Test of Visual Perceptual Skills in Normal Children Aged 4 to 6 Years in Tehran City [dissertation]. Rehabilitation and Welfare Rehabilitation and Welfare Univ; 2004.

35. Sloan W. The Lincoln-Oseretsky motor development scale. Genet Psychol Monogr. 1955;51(2):183.

36. Zarezadeh M, Farokhi A, Kazem N, A. Determining reliability and validity of test of gross motor development (Ulrich, 2000) in 3-11 aged children of Tehran city. OLYMPIC. 2011;18(4):85-98.

37. Araújo S, Reis A, Petersson KM, Faísca L. Rapid automatized naming and reading performance: A meta-analysis. J Educ Psychol. 2015;107(3):868.

38. Nag S, Snowling MJ. Cognitive profiles of poor readers of Kannada. Read Writ. 2011;24(6):657-76.

39. Papadimitriou AM, Vlachos FM. Which specific skills developing during preschool years predict the reading performance in the first and second grade of primary school? Early Child Dev Care. 2014;184(11):1706-22.

40. Rothou KM, Padeliadu S, Sideridis GD. Predicting early reading in greek: the contribution of phonological awareness and nonphonological language skills. Procedia Soc Behav Sci. 2013;93:15049.

41. Jiang X. The role of first language literacy and second language proficiency in second language reading comprehension. RM. 2011;11(2).

42. Marinova-Todd SH, Zhao J, Bernhardt M. Phonological awareness skills in the two languages of Mandarin-English bilingual children. Clin Linguist Phon. 2010;24(4-5):387-400.

43. Kita Y, Suzuki K, Hirata S, Sakihara K, Inagaki M, Nakai A. Applicability of the Movement Assessment Battery for Children-to Japanese children: A study of the Age Band 2. Brain Dev. 2016;38(8):706-13. 